\title{
Mitochondrial $\mathrm{NADP}^{+}$-dependent isocitrate dehydrogenase deficiency increases cisplatin-induced oxidative damage in the kidney tubule cells
}

\author{
Min Jung Kong', Sang Jun Han', Jee In Kim², Jeen-Woo Park ${ }^{3}$ and Kwon Moo Park ${ }^{1}$
}

\begin{abstract}
Mitochondrial $\mathrm{NADP}^{+}$-dependent isocitrate dehydrogenase (IDH2) plays an important role in the formation of NADPH, which is critical for the maintenance of mitochondrial redox balance. Cis-diamminedichloroplatinum II (cisplatin), an effective anticancer drug, induces oxidative stress-related nephrotoxicity, limiting its use. Therefore, we investigated whether IDH2, which is a critical enzyme in the NADPH-associated mitochondrial antioxidant system, is involved in cisplatin nephrotoxicity. Idh2 gene-deleted $\left(I d h 2^{-/-}\right)$mice and wild-type $\left(I d h 2^{+/+}\right)$littermates were treated with cisplatin, with or without 2-(2,2,6,6-tetramethylpiperidin-1-oxyl-4-ylamino)-2-oxoethyl) triphenylphosphonium chloride (Mito-T), a mitochondria-specific antioxidant. Cisplatin-induced renal functional and morphological impairments were greater in $/ d h 2^{-/-}$mice than in $/ d h 2^{+/+}$mice. Mito-T mitigated those impairments in both $/ d h 2^{-/-}$and $/ d h 2^{+/+}$mice and this mitigation was greater in $/ d h 2^{-/-}$than in $/ d h 2^{+/+}$mice. Cisplatin impaired IDH2 function in the mitochondria, decreasing mitochondrial NADPH and GSH levels and increasing $\mathrm{H}_{2} \mathrm{O}_{2}$ generation; protein, lipid, and DNA oxidation; mitochondrial damage; and apoptosis. These cisplatin-induced changes were much more severe in $/ \mathrm{dh} 2^{-/-}$mice than in $I d h 2^{+/+}$mice. Mito-T treatment attenuated cisplatin-induced alterations in both $/ d h 2^{-/-}$and $l d h 2^{+/+}$mice and this mitigation was greater in $I d h 2^{-/-}$than in $I d h 2^{+/+}$mice. Altogether, these data demonstrate that cisplatin induces the impairment of the mitochondrial IDH2-NADPH-GSH antioxidant system and IDH2 deficiency aggravates cisplatininduced mitochondrial oxidative damage, inducing more severe nephrotoxicity. This suggests that the mitochondrial IDH2-NADPH-GSH antioxidant system is a target for the prevention of cisplatin-induced kidney cell death.
\end{abstract}

\section{Introduction}

Cisplatin (cis-diamminedichloroplatinum II) is widely used as an effective chemotherapeutic reagent for malignant tumors. However, its nephrotoxicity limits its use $\mathrm{e}^{1,2}$. This cisplatin nephrotoxicity, which causes acute kidney injury (AKI), is associated with oxidative stress of kidney

\footnotetext{
Correspondence: Kwon Moo. Park (kmpark@knu.ac.kr)

${ }^{1}$ Department of Anatomy, Cardiovascular Research Institute and BK21 Plus, School of Medicine, Kyungpook National University, 680 Gukchaebosang-ro, Junggu, Daegu 41944, Republic of Korea

${ }^{2}$ Department of Molecular Medicine and MRC, Keimyung University School of Medicine, 1095 Dalgubeol-daero, Dalseogu, Daegu 42601, Republic of Korea Full list of author information is available at the end of the article

Edited by E Baehrecke
}

tubular cells. Recent studies have demonstrated that cisplatin toxicity is highly associated with mitochondrial oxidative stress and subsequent mitochondrial dysfunction and cell death ${ }^{3-5}$. Cisplatin accumulates in the mitochondria of renal epithelial cells during excretion of cisplatin metabolites through renal tubules and further forms a cisplatin-glutathione (GSH) complex, which is easily released to the extracellular matrix through organic cation transporter 1 (OCT1) and copper transporter (Ctr1), consequently reducing mitochondrial GSH levels ${ }^{6}$. This causes the impairment of the GSH-associated mitochondrial antioxidant system, consequently increasing mitochondrial susceptibility to oxidative stress ${ }^{3,6-8}$.

\section{(c) The Author(s) 2018}

(c) (i) Open Access This article is licensed under a Creative Commons Attribution 4.0 International License, which permits use, sharing, adaptation, distribution and reproduction in any medium or format, as long as you give appropriate credit to the original author(s) and the source, provide a link to the Creative Commons license, and indicate if changes were made. The images or other third party material in this article are included in the article's Creative Commons license, unless indicated otherwise in a credit line to the material. If material is not included in the article's Creative Commons license and your intended use is not permitted by statutory regulation or exceeds the permitted use, you will need to obtain permission directly from the copyright holder. To view a copy of this license, visit http://creativecommons.org/licenses/by/4.0/. 


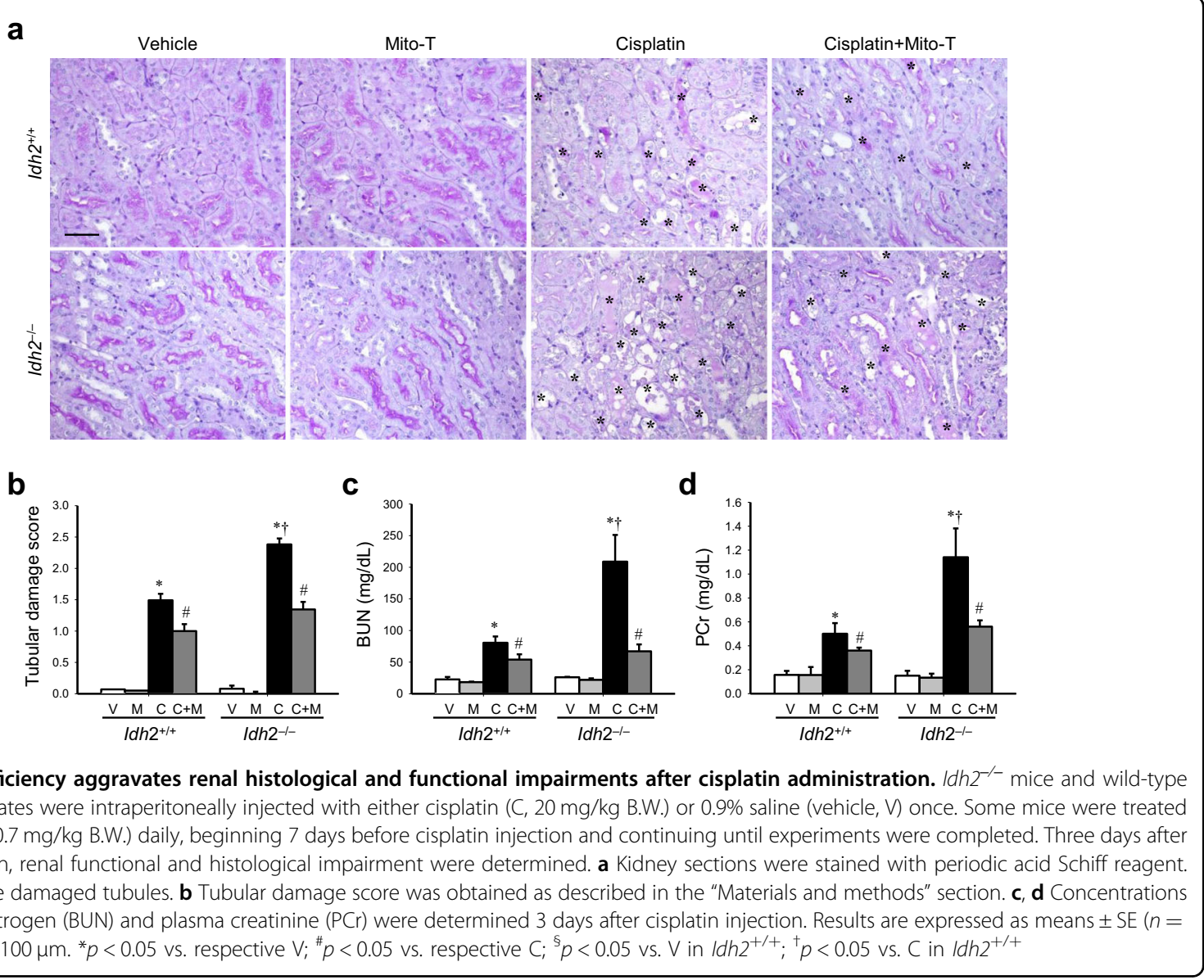

Mitochondrial respiration produces reactive oxygen species (ROS), which can induce oxidative stress to cellular components, consequently leading to cell dysfunction and death. Therefore, mitochondria are well equipped with various antioxidant systems to cope with oxidative stress. However, pathological conditions, such as cisplatin nephrotoxicity, cause functional loss of mitochondrial antioxidant systems and overproduction of ROS, overwhelming their antioxidant capacity $^{9,10}$. Mitochondrial oxidative stress eventually leads to mitochondrial dysfunction and damage, which can induce cell death ${ }^{11-13}$. In normal conditions, the superoxide anion produced in the mitochondria during mitochondrial respiration is primarily converted to toxic $\mathrm{H}_{2} \mathrm{O}_{2}$ by manganese superoxide dismutase (MnSOD). $\mathrm{H}_{2} \mathrm{O}_{2}$ is then further reduced to $\mathrm{H}_{2} \mathrm{O}$ by catalase, glutathione peroxidase (GSH$\mathrm{Px}$ ), and thiol-containing enzymes, such as thioredoxins (Trx), thioredoxin reductases ( $\operatorname{TrR})$, peroxiredoxins (Prx), and glutaredoxins ${ }^{12,14,15}$. GSH-Px is a family of tetrameric enzymes that contain the unique amino acid, selenocysteine, within their active sites and use low-molecular weight thiols, such as $\mathrm{GSH}$, to reduce $\mathrm{H}_{2} \mathrm{O}_{2}{ }^{14}$. NADPH is commonly required for these antioxidants to provide a reducing equivalent, it maintains catalase in the active form, and it is used as a cofactor by TRX and glutathione reductase (GR), which convert oxidized GSH (GSSG) to GSH, a co-substrate for GSH-Px enzymes ${ }^{14}$. Therefore, NADPH is critical for the GSH-associated mitochondrial antioxidant system.

Intracellular NADPH is mainly generated by the reduction of $\mathrm{NADP}^{+}$by glucose-6-phosphate dehydrogenase (G6PD) in the cytosol and $\mathrm{NADP}^{+}$-dependent isocitrate dehydrogenase 2 (IDH2) in the mitochondria ${ }^{16}$. Isocitrate dehydrogenases (IDHs) catalyze the oxidative decarboxylation of isocitrate to $\alpha$-ketoglutarate, accompanied by the reduction of NAD $(\mathrm{P})^{+}$to $\mathrm{NAD}(\mathrm{P}) \mathrm{H}$. Three IDHs, IDH1, IDH2, and IDH3, are present in mammals ${ }^{17}$. IDH1 and IDH2 are $\mathrm{NADP}^{+}$-dependent and they are localized in the cytosol and mitochondria, respectively ${ }^{17}$. IDH3 is $\mathrm{NAD}^{+}$-dependent and is localized in the mitochondria ${ }^{17}$. Recent evidence has demonstrated that NADPH levels generated by IDH1 and IDH2 are critical for the maintenance of redox balance via the GSH and thioredoxin systems of peroxide detoxification ${ }^{18-21}$.

Therefore, we hypothesized that IDH2 may be associated with cisplatin-induced AKI. In this study, we investigated the involvement of IDH2 in the mitochondrial NADPH-GSH antioxidant system in cisplatin 


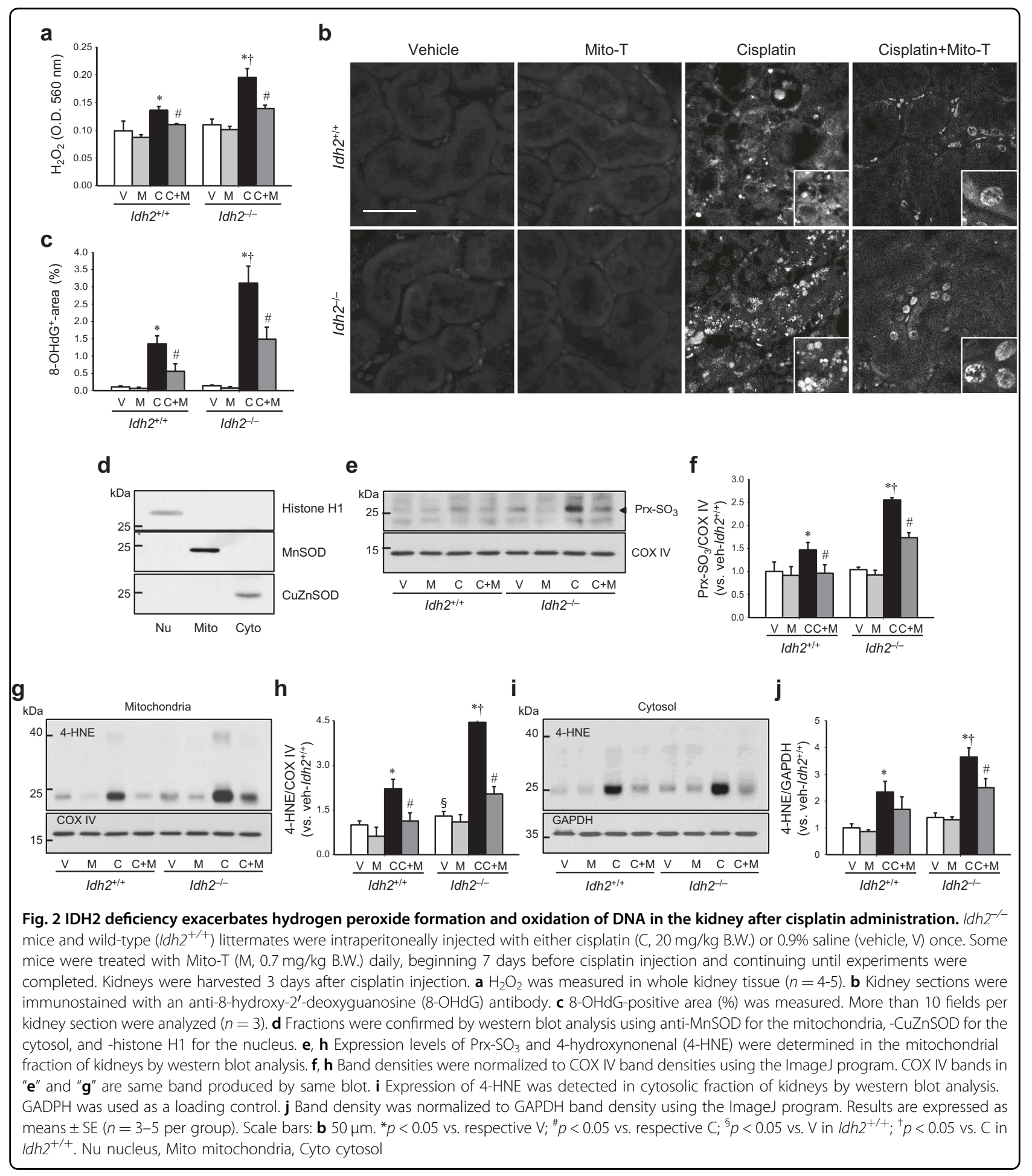

nephrotoxicity using Idh2 gene-deleted mice. Here, we report that cisplatin impairs the IDH2-NADPH-GSHassociated antioxidant system in the mitochondria, leading to mitochondrial oxidative stress and eventually, kidney tubular cell death and kidney dysfunction.

\section{Results}

IDH2 deficiency aggravates renal morphological and functional impairments after cisplatin administration

To investigate whether IDH2 deletion affects cisplatininduced AKI, we evaluated kidney morphology and 
function. Cisplatin induced the loss of the brush border in tubular epithelial cells and dilation and congestion of tubules in both $I d h 2^{+/+}$and $I d h 2^{-/-}$mice (Fig. 1a, b). Tubular cell damage was greatest in the proximal tubular cells compared with other tubular cells (Fig. 1a). Consistent with tubular damage, blood urea nitrogen (BUN) and plasma creatinine (PCr) levels were markedly increased in the cisplatin-treated mice (Fig. 1c, d). These morphological and functional effects in the kidney after cisplatin injection were higher in $I d h 2^{-/-}$mice than in wild-type littermates (Fig. 1). Mito-T, a mitochondriatargeting antioxidant molecule, ameliorated this cisplatininduced histological and functional damage in both $I d h 2^{+/+}$and $I d h 2^{-/-}$mice and this amelioration was more profound in $I d h 2^{-/-}$mice than in $I d h 2^{+/+}$mice (Fig. 1); Mito- $\mathrm{T}$ treatment reduced tubular damage score by $\sim 45 \%$ and $27 \%$ in cisplatin-injected $I d h 2^{-/-}$and $I d h 2^{+/+}$mice, respectively (Fig. 1b). The decreases in BUN after Mito- $\mathrm{T}$ treatment were $\sim 68 \%$ and $30 \%$ in $I d h 2^{-/-}$and $I d h 2^{+/+}$ mice, respectively (Fig. 1c). Reductions of PCr after Mito$\mathrm{T}$ treatment were $\sim 51 \%$ and $28 \%$ in $I d h 2^{-/-}$and $I d h 2^{+/+}$ mice, respectively (Fig. 1d). These results indicate that IDH2 deficiency elevates cisplatin nephrotoxicity.

\section{IDH2 deficiency augments mitochondrial oxidative stress after cisplatin administration}

To investigate whether high susceptibility to cisplatin in Idh2-gene-deficient mice is associated with oxidative stress, we first determined ROS formation in the kidney. Cisplatin injection increased $\mathrm{H}_{2} \mathrm{O}_{2}$ production and 8OHdG, an index of oxidized DNA, signals in both $I d h 2^{+/+}$ and $I d h 2^{-/-}$mouse kidneys and these cisplatin-induced increases were higher in $I d h 2^{-/-}$mice than in $I d h 2^{+/+}$ mice (Fig. 2a-c). The 8-OHdG antibody binds to DNA damaged by oxidation in mitochondria and nuclei ${ }^{22}$. Therefore, these increased 8-OHdG signals indicate increased nuclear and mitochondrial DNA oxidation. Next, we measured the mitochondrial oxidative stress by western blot analysis using anti-Prx- $\mathrm{SO}_{3}$, an oxidized form of Prx, and -4-hydroxynoneal (4-HNE), an oxidized lipid, antibody in the mitochondria. Mitochondrial and cytosolic fraction was confirmed through western blot analysis using anti-manganese superoxide dismutase (MnSOD) for the mitochondria, -copper-zinc superoxide dismutase (CuZnSOD) for the cytosol, and -histone H1 for the nucleus antibodies, respectively (Fig. 2d). Mitochondrial $\mathrm{Prx}-\mathrm{SO}_{3}$ and 4-HNE expression also increased in cisplatin-injected mice and these increases were greater in $I d h 2^{-/-}$mice than in $I d h 2^{+/+}$mice (Fig. 2e-h). In addition, we determined 4-HNE expression in cytosol, since mitochondrial oxidative stress can extend into the cytosol, and vice versa. 4-HNE expression in the cytosol also increased in cisplatin-injected mice and this increase was greater in $I d h 2^{-/-}$mice than in $I d h 2^{+/+}$mice (Fig. $2 \mathrm{i}, \mathrm{j}$ ).
These cisplatin-induced increases in $\mathrm{H}_{2} \mathrm{O}_{2}, 8-\mathrm{OHdG}$, Prx- $-\mathrm{SO}_{3}$, and 4-HNE were significantly attenuated by Mito- $\mathrm{T}$ treatment in both $I d h 2^{-/-}$and $I d h 2^{+/+}$mouse kidneys (Fig. 2). Attenuation by Mito-T was greater in $I d h 2^{-/-}$mice than in $I d h 2^{+/+}$mice (Fig. 2). Taken together, these results indicate that cisplatin induces mitochondrial oxidative stress and IDH2 deficiency augments cisplatininduced mitochondrial oxidative injury. Therefore, increased susceptibility caused by Idh2 gene deletion may be associated with the increased mitochondrial damage.

\section{Cisplatin impairs the IDH2-NADPH-GSH-associated mitochondrial antioxidant system and Idh2 gene deletion exacerbates this cisplatin-induced impairment}

First, we determined whether cisplatin affects IDH2 function and expression. Cisplatin injection greatly decreased the activity of IDH2 in the mitochondria from 1 day after injection with mild or no increase in the expression level (Fig. 3b, c, e), even when increases of BUN and 4-HNE expression were not observed, or very mild (Fig. 3a, b, d). The decrease of IDH2 activity was exacerbated overtime in a time-dependent manner (Fig. 3e). IDH2 expression also decreased after cisplatin injection in the same pattern as activity (Fig. 3b, c). Cisplatin also decreased IDH1 activity in cytosol. This decrease in IDH1 activity was less when compared with the decrease of IDH2 activity (Fig. 3f). However, IDH3 activity in the mitochondria was not significantly changed after cisplatin injection (Fig. 3g). Although these results cannot provide an answer regarding causality, the above data suggest that the decrease of IDH2 function through cisplatin could be a cause at least in part.

Next, we determined whether cisplatin decreased NADPH levels in the mitochondria in both $I d h 2^{+/+}$mice and $I d h 2^{-1-}$ mice (Fig. 3h). Compared to Idh $2^{+/+}$mice, $I d h 2^{-1-}$ mice showed a greater decrease in NADPH level after cisplatin injection (Fig. 3h). NADPH levels in the mitochondrial fraction of vehicle-treated $I d h 2^{-/-}$mouse kidneys were lower than that in vehicle-treated $I d h 2^{+/+}$ mice (Fig. 3h). In addition, cisplatin reduced IDH2 expression and this reduction was prevented by Mito- $\mathrm{T}$ treatment (Fig. 3i, j). These results indicate that IDH2 regulates NADPH level in the mitochondria and cisplatin impairs the NADPH-producing system of mitochondria.

Further, we determined the ratio of oxidized glutathione (GSSG) to total glutathione (tGSH) in the mitochondrial fraction of kidneys, because NADPH plays a critical role in the reduction of GSSG to GSH. After cisplatin treatment, mitochondrial GSSG levels increased in both $I d h 2^{+/+}$and $I d h 2^{-/-}$mouse kidneys, whereas GSH levels decreased (Fig. 4a, b). These changes increased the GSSG/ tGSH ratio in both $I d h 2^{+/+}$and $I d h 2^{-/-}$mice, showing a higher increase in $I d h 2^{-/-}$mouse kidneys than in $I d h 2^{+/+}$ 


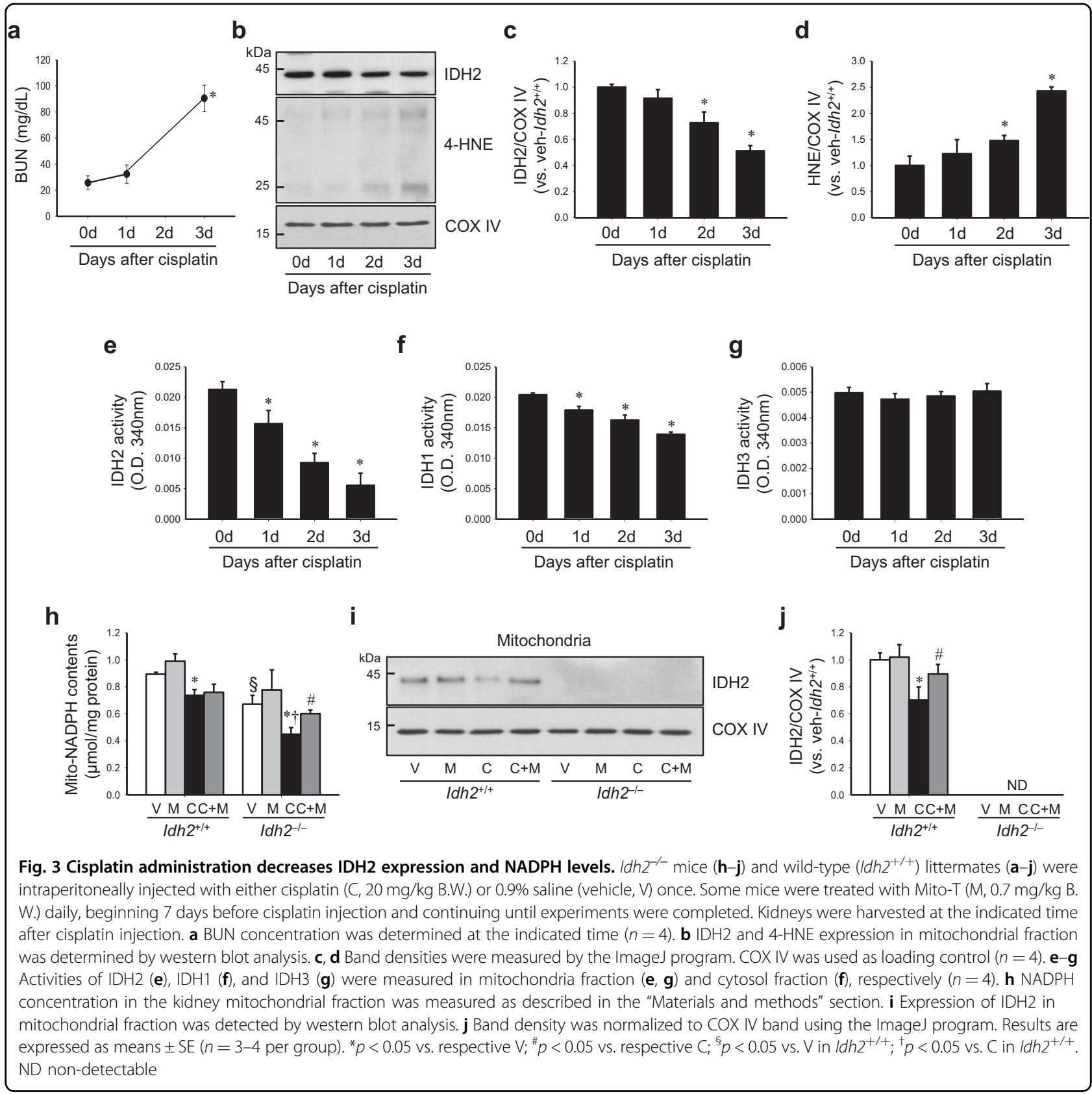

mouse kidneys (Fig. 4c). Mito-T significantly attenuated the cisplatin-induced changes in GSSG and GSH in both mice. However, these mitigations after Mito- $\mathrm{T}$ treatment were more prominent in $I d h 2^{-/-}$mice compared with their wild-type littermates (Fig. 4a-e).

Finally, we determined the activity of GSH-Px, which uses GSH as a substrate, and GR, which reduces GSSG to GSH using NADPH ${ }^{12}$. Mitochondrial GSH-Px and GR activities decreased in both $I d h 2^{+/+}$and $I d h 2^{-/-}$mice after cisplatin injection (Fig. 4d, e). These reduced activities were greater in $I d h 2^{-/-}$mice than in $I d h 2^{+/+}$mice (Fig. 4d, e). The reduction in GSH-Px and GR activities was significantly attenuated by Mito- $\mathrm{T}$ and this attenuation was higher in $I d h 2^{-/-}$than in $I d h 2^{+/+}$mice (Fig. $4 \mathrm{~d}$, e). These data indicate that cisplatin impairs the mitochondrial NADPH-GSH antioxidant system.

\section{IDH2 deficiency accelerates mitochondrial damage following cisplatin administration}

Oxidative stress in mitochondria induces mitochondrial dysfunction and a shift of the mitochondrial dynamics toward fission, leading to mitochondrial fragmentation and activation of the apoptotic signal pathway ${ }^{23,24}$. Therefore, we investigated whether increased susceptibility to cisplatin in 

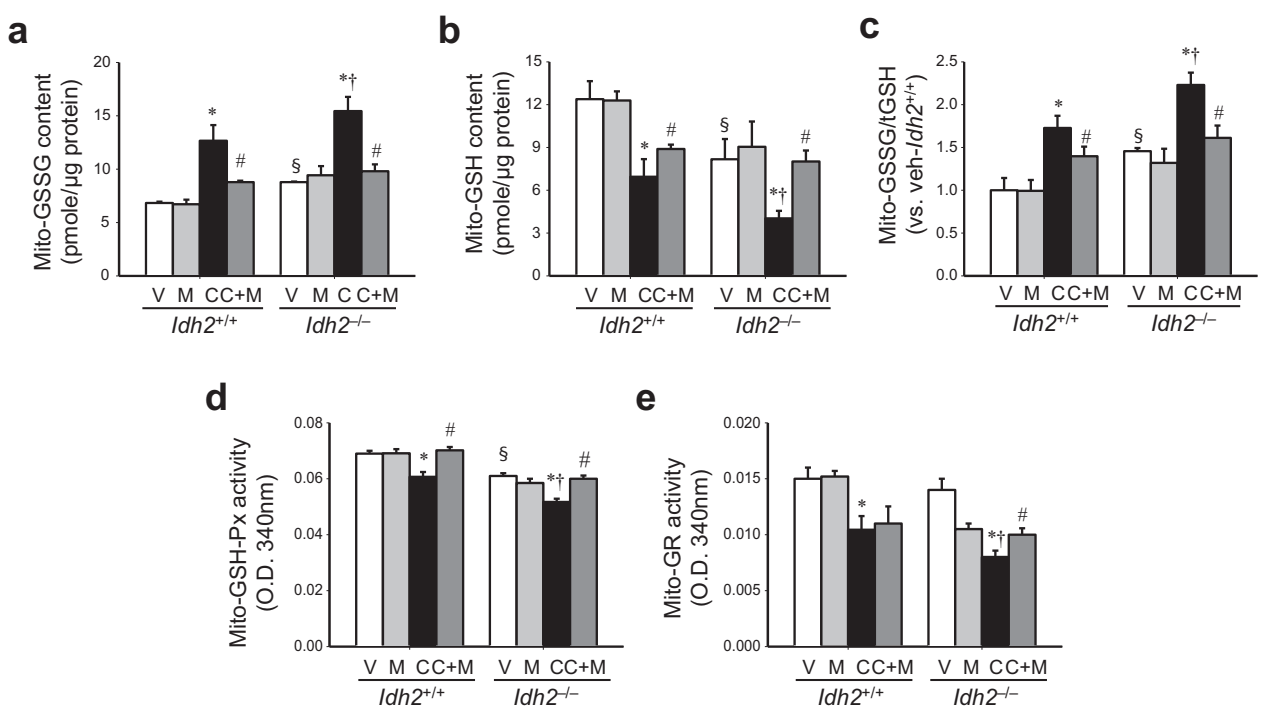

Fig. 4 Cisplatin administration impairs the mitochondrial GSH-mediated antioxidant system in the kidney. Idh $2^{-/-}$mice and wild-type (Idh $2^{+/}$ ${ }^{+}$) littermates were intraperitoneally injected with either cisplatin (C, $20 \mathrm{mg} / \mathrm{kg}$ B.W.) or $0.9 \%$ saline (vehicle, V) once. Some mice were treated with Mito-T (M, 0.7 mg/kg B.W.) daily, beginning 7 days before cisplatin injection and continuing until experiments were completed. Kidneys were harvested 3 days after cisplatin injection. a-c Oxidized GSH (GSSG) levels (a), reduced GSH levels (b), and the GSSG/tGSH ratio (c) were determined in mitochondrial fractions. d, e GSH-Px (d) and GR (e) activities were measured in mitochondrial fractions. Results are expressed as means \pm SE $(n=4$ per group). ${ }^{*} p<0.05$ vs. respective $V ;{ }^{\#} p<0.05$ vs. respective $C ;{ }^{\S} p<0.05$ vs. $V$ in $1 d h 2^{+/+} ;{ }^{\dagger} p<0.05$ vs. $C$ in $1 d h 2^{+/+}$

$I d h 2^{-/-}$mice is associated with mitochondrial damage. Cisplatin induced damage of mitochondria in the proximal tubular cells of both $I d h 2^{+/+}$and $I d h 2^{-/-}$mouse kidneys (Fig. 5a). This mitochondrial damage was more severe in $I d h 2^{-/-}$mice than in $I d h 2^{+/+}$mice together with higher mitochondrial aspect ratio [(major axis/minor axis)] in the $I d h 2^{-/-}$mice than Idh2 $2^{+/+}$mice (Fig. 5a, b). Because mitochondrial fragmentation is associated with regulatory proteins of mitochondrial fusion and fission ${ }^{9}$, we determined the expression of mitochondrial fusion and fission regulatory proteins. Cisplatin decreased the expression of Opa1, a regulator of mitochondrial fusion, in both $I d h 2^{+/+}$ and $I d h 2^{-/-}$mouse kidneys (Fig. 5c, d). Conversely, Drp1, a mitochondria fission protein, was increased by cisplatin administration (Fig. 5c, e). These cisplatin-induced alterations in Opa1 and Drp1 expression were greater in $I d h 2^{-/-}$than in Idh2 $2^{+/+}$mice (Fig. $5 \mathrm{c}-\mathrm{e}$ ). Mito-T treatment preserved mitochondrial morphology (Fig. 5a) and significantly mitigated the changes in Opa1 and Drp1 expression in both $I d h 2^{+/+}$and $I d h 2^{-/-}$mice (Fig. $5 \mathrm{c}-\mathrm{e}$ ). These Mito-T effects were more dramatic in $I d h 2^{-/-}$mice than in their wild-type littermates (Fig. 5c-e). These results indicate that $I d h 2$ gene deletion exacerbates cisplatin-induced mitochondrial damage.

\section{IDH2 deficiency augments apoptosis after cisplatin administration}

Because mitochondrial oxidative stress activates apoptosis signaling pathways ${ }^{13,25}$, we examined whether Idh2 gene deletion affects apoptosis after cisplatin injection. First, we investigated the responses of the apoptosis regulatory signal pathway after cisplatin injection in both $I d h 2^{+/+}$and $I d h 2^{-/-}$mouse kidneys. Cisplatin increased Bax expression, whereas it decreased $\mathrm{Bcl}-2$ expression in both $I d h 2^{+/+}$and $I d h 2^{-/-}$mouse kidneys. Changes in expression were greater in $I d h 2^{-/-}$than in $I d h 2^{+/+}$mice (Fig. 6a-c). Mito-T treatment significantly inhibited the cisplatin-induced increase in Bax, but not $\mathrm{Bcl}-2$ expression (Fig. 6a-c). Cisplatin induced the release of cytochrome $c$ from mitochondria into the cytosol in both $I d h 2^{+/+}$and $I d h 2^{-/-}$mice, and this release was greater in $I d h 2^{-/-}$mice than in Idh2 $2^{+/+}$mice (Fig. 6d-f). Cleaved caspase- 3 expression levels were also elevated by cisplatin injection in both $I d h 2^{+/+}$and $I d h 2^{-/-}$mice, and this elevation was greater in $I d h 2^{-/-}$mice than in $I d h 2^{+/+}$mice (Fig. 6g, h). Mito-T reduced cytochrome $c$ release and cleavage of caspase- 3 in both $I d h 2^{-/-}$and $I d h 2^{+/+}$mice, showing a greater reduction in $I d h 2^{-/-}$mice than in Idh2 $2^{+/+}$mice (Fig. 6d-h).

Finally, we determined the apoptosis of kidney tubular cells by terminal deoxynucleotidyl transferase dUTP nick end labeling (TUNEL) analysis. Cisplatin injection increased the number of TUNEL-positive tubular epithelial cells (Fig. 7a). This increase in TUNEL-positive cells was greater in $I d h 2^{-/-}$mice than in their wild-type littermates (Fig. 7a, b). Mito-T reduced the cisplatininduced increase in TUNEL-positive cells in both Idh2 $2^{-/-}$ and $I d h 2^{+/+}$mice (Fig. 7a, b). This effect of Mito-T was 

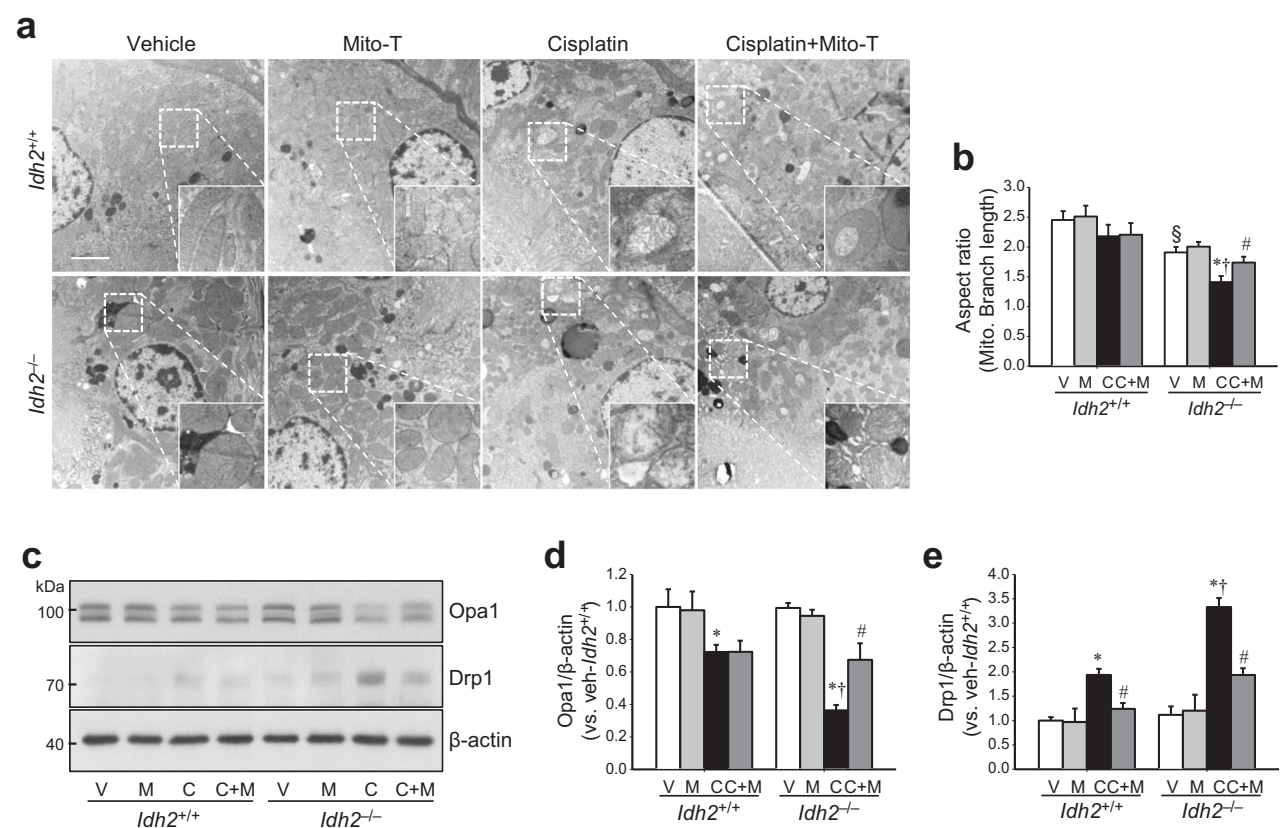

Fig. 5 IDH2 deficiency augments mitochondrial damage after cisplatin administration. $/ d h 2^{-/-}$mice and wild-type $\left(I d h 2^{+/+}\right)$littermates were intraperitoneally injected with either cisplatin (C, 20 mg/kg B.W.) or $0.9 \%$ saline (vehicle, V) once. Some mice were treated with Mito-T ( $M, 0.7$ mg/kg B. W.) daily, beginning 7 days before cisplatin injection and continuing until experiments were completed. a Two days after cisplatin administration, mitochondrial structures were examined by transmission electron microscopy (TEM). Higher magnification is shown by the dash-lined rectangles. Scale bar indicates $2 \mu \mathrm{m}$. b The mitochondrial aspect ratio [(major axis)/(minor axis)] was computed using 30 mitochondria per cell. c Expressions of OPa1 and Drp1 were determined by western blot analysis. $\beta$-actin was used as a loading control. d, e OPa1 (d) and Drp1 (e) band densities were measured using the ImageJ program. Results are expressed as means \pm SE $\left(n=3-4\right.$ per group). Scale bars: a $2 \mu m$. ${ }^{*} p<0.05$ vs. respective $V_{;}{ }^{\#} p<0.05$ vs. respective $C_{i}{ }^{\$} p<0.05$ vs. V in $l d h 2^{+/+} ;{ }^{\dagger} p<0.05$ vs. $C$ in $/ d h 2^{+/+}$

greater in $I d h 2^{-/-}$mice than in $I d h 2^{+/+}$mice (Fig. 7a, b). These results indicate that IDH2 deficiency exacerbates cisplatin-induced apoptosis, which is associated with mitochondrial oxidative stress.

\section{Discussion}

In the present study, we have reported, for the first time, that cisplatin impairs the mitochondrial IDH2-NADPHGSH antioxidant system, leading to mitochondrial oxidative stress and consequently, renal cell death and dysfunction. In addition, Idh2 gene deletion reduces mitochondrial NADPH levels and exacerbates cisplatininduced mitochondrial oxidative stress and kidney injury. Furthermore, the mitochondria-targeting antioxidant, Mito- $T$, mitigates cisplatin nephrotoxicity. These findings suggest that IDH2 is associated with cisplatin-induced nephrotoxicity and the IDH2-NADPH-GSH axis considered as a target pathway to develop preventive treatments for cisplatin nephrotoxicity and AKI.

When cisplatin is excreted through urination, cisplatin accumulates in kidney cells by uptake through OCT1 and Ctr1, which are highly expressed on kidney tubular epithelial cells ${ }^{6,7}$. Cisplatin metabolites have a positive charge by hydration and therefore, easily penetrate the mitochondrial membrane, because the mitochondria has a negative membrane potential $(\sim 180 \mathrm{mV})$. The metabolites then accumulate in the mitochondria and combine with negatively charged mitochondrial components, such as DNA, RNA, and proteins, leading to loss of function, including their antioxidant functions ${ }^{26,27}$. Therefore, mitochondria-rich cells, such as proximal tubular cells, are very susceptible to cisplatin ${ }^{25}$. In the present study, we found that proximal tubular cell damage is most severe among kidney tubular cells, suggesting that cisplatin nephrotoxicity is associated with mitochondrial density and damage. Because IDH2 is abundant in the proximal tubular cells ${ }^{16}$, Idh2-gene-deleted mice may be more susceptible to cisplatin toxicity in these cells.

Cisplatin induces ROS formation by inhibiting complexes I-IV of the respiratory chain and inhibiting GR function, which leads to decreased GSH levels, consequently resulting in increased mitochondrial ROS and oxidative stress, which can expand to entire cells ${ }^{28}$. Many studies have demonstrated that the reduction of mitochondrial ROS attenuates renal injury during cisplatin administration $^{11,29,30}$. On the contrary, weakening of antioxidant capacity, such as by GSH deletion, exacerbates cisplatin nephrotoxicity ${ }^{30}$. Furthermore, cisplatin 


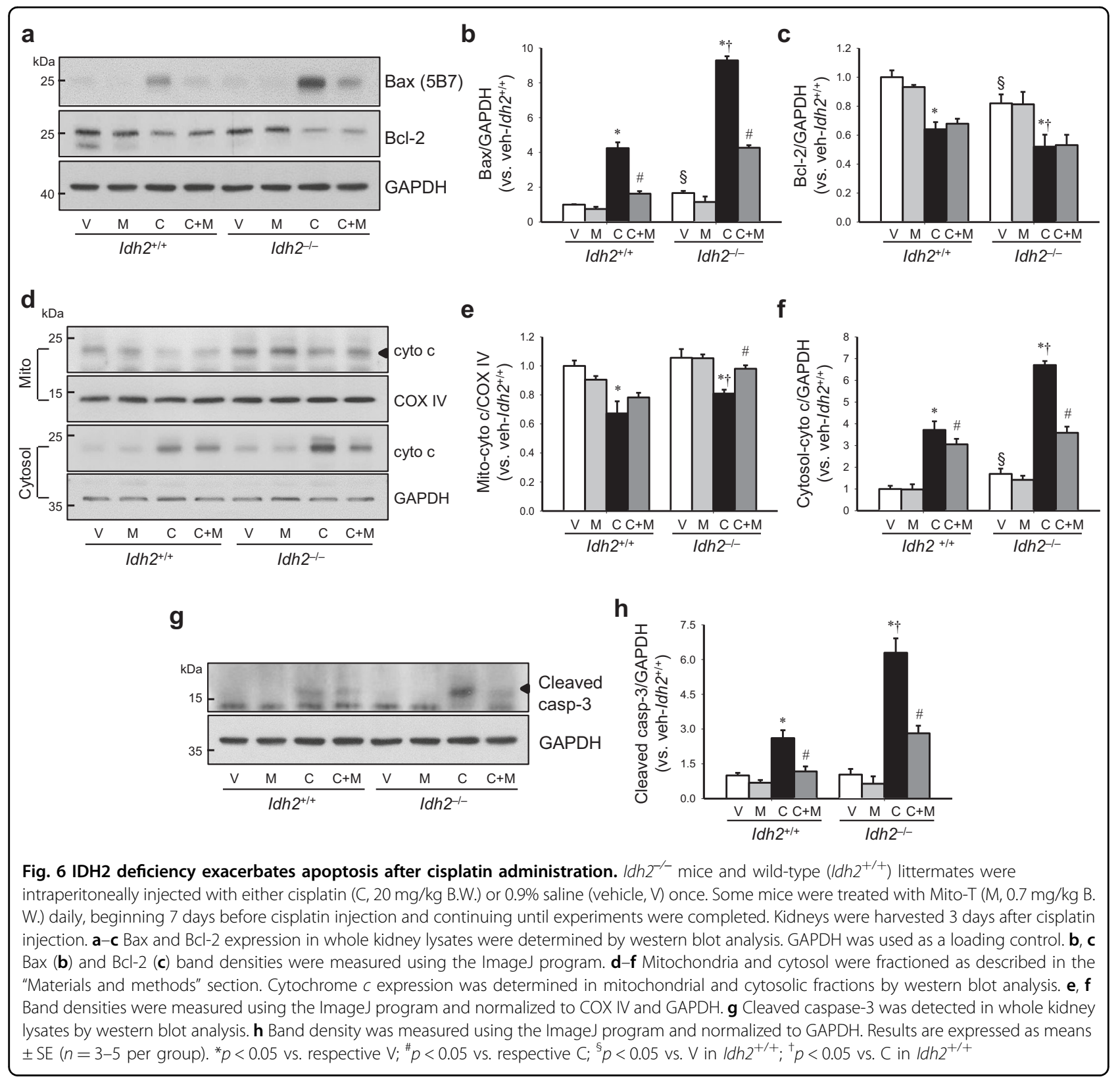

decreased mitochondrial GSH levels and GSH-Px and GR activity, leading to increases in mitochondrial $\mathrm{H}_{2} \mathrm{O}_{2}$ levels; oxidation of DNA, proteins, and lipids; mitochondrial swelling; cristae loss; and a shift to fission in proximal tubular cells. These cisplatin-induced changes were enhanced by Idh2 gene deletion, whereas a mitochondriatargeting antioxidant inhibited these cisplatin-induced changes in both $I d h 2^{-/-}$and $I d h 2^{+/+}$mice, but with a greater effect in $I d h 2^{-/-}$mice. In addition, in this present study we found that the activity of IDH2 declined from 1 day after cisplatin injection, when renal functional impairment and oxidative stress are very mild or absent. This result indicates that cisplatin impairs IDH2 function, suggesting that the decline of IDH2 activity is not only a secondary response to oxidative stress, but also a primary response in cisplatin-nephrotoxicity. However, to define how cisplatin impairs IDH2 function, further studies are required.

NADPH is essential for the GSH-associated mitochondrial antioxidant system by providing a reducing equivalent, maintaining catalase in the active form, and acting as a cofactor for Trx and GR, which convert GSSG to GSH, a substrate for the GSH-Px enzymes ${ }^{14}$. NADPH does not shuttle between the mitochondria and the cytosol ${ }^{14,31}$. We found that IDH1 activity declined after cisplatin injection, although the decline was relatively milder than the decline 


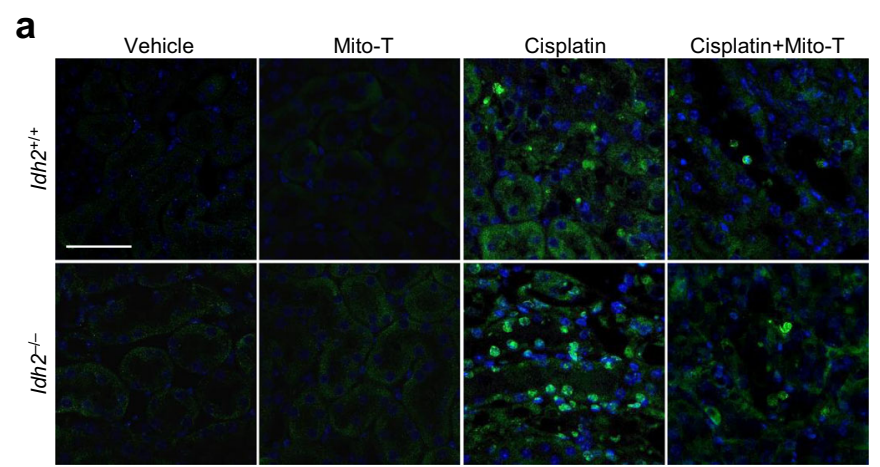

b

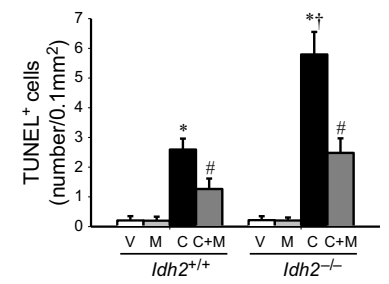

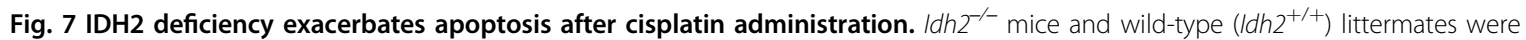
intraperitoneally injected with either cisplatin (C, 20 mg/kg B.W.) or $0.9 \%$ saline (vehicle, V) once. Some mice were treated with Mito- $T$ ( $M$, 0.7 mg/kg B. W.) daily, beginning 7 days before cisplatin injection and continuing until experiments were completed. Kidneys were harvested 3 days after cisplatin injection. Kidney sections were stained using a TUNEL assay kit. a Immunostaining shows TUNEL-positive cells (green). Nuclei were stained with DAPI (blue). b TUNEL-positive cells were counted in 10 fields per kidney. Results are expressed as means \pm SE ( $n=3$ per group). Scale bars: a $50 \mu \mathrm{m}$. ${ }^{*} p<$ 0.05 vs. respective $V_{;}{ }^{\#} p<0.05$ vs. respective $C_{i}{ }^{\dagger} p<0.05$ vs. $C$ in $/ d h 2^{+/+}$

of IDH2 activity. This suggests that, although cisplatin toxicity is associated with both IDH1 and IDH2, IDH2 plays more critical role in cisplatin nephrotoxicity. We speculate that the smaller decline in IDH1 may be due to the functions of enzymes that produce NADPH. NADPH in the cytosol is mainly produced by G6PD ${ }^{19}$. However, mitochondrial oxidative stress extends into the cytosol, and vice versa, hence IDH1 can be also associated with cisplatin-induced nephrotoxicity. Since IDH3 is a family member of IDH, although IDH3 is not critically involved in the production of $\mathrm{NADPH}^{19}$, we determined IDH3 activity. As expected, we did not find any significant change in IDH3 activity in the kidneys after cisplatin injection. Therefore, these data indicate that mitochondrial NADPH production by IDH2 is critical for the maintenance of mitochondrial redox balance. In the present study, we found that $I d h 2$ gene deletion decreased $\mathrm{NADPH}$ levels in kidney. The Idh2 gene deletion also decreased GSH levels in the mitochondria of kidney cells. Furthermore, Idh2 gene deletion augmented the cisplatininduced increase in the GSSG/tGSH ratio and decreased GSH-Px and GR activities in the mitochondrial fraction of kidneys. These data indicate that IDH2 regulates mitochondrial NADPH levels and mitochondrial GSHassociated antioxidant systems, suggesting that IDH2 is involved in cisplatin-induced nephrotoxicity via affecting mitochondrial NADPH levels.

Increased oxidative stress causes mitochondrial fragmentation and enhances the release of mitochondria apoptotic factors, leading to cell death ${ }^{9,2332,33}$. In the present study, cisplatin induced severe mitochondrial injury and dysfunction and disturbed the balance of mitochondrial fission and fusion protein expression, resulting in a shift of mitochondria to fission, which then increased mitochondria fragmentation. Idh2 gene deletion promoted this cisplatin-induced mitochondrial damage. Furthermore, disruption of mitochondria leads to translocation of the pro-apoptotic factor, Bax, from the cytosol to mitochondria and degradation of anti-apoptotic proteins, such as Bcl-2, leading to apoptosis and/or necro$\operatorname{sis}^{4,9,32}$. Wang et el. reported that Drp1, a mitochondrial fission protein, activates Bax translocation from the cytosol to mitochondria, leading to the formation of a mitochondrial membrane pore, consequently resulting in the release of cytochrome $c$ to the cytosol ${ }^{34}$. In the present study, cisplatin induced the release of cytochrome $c$ from mitochondria to the cytosol, with increases in Drp1 and Bax expression. These cisplatin-induced alterations were greater in $I d h 2^{-/-}$mice than in wild-type mice. These data indicate that increased mitochondrial oxidative stress in $I d h 2^{-/-}$mice is associated with mitochondrial fragmentation and activation of apoptosis signaling pathways. It has been reported that, when ROS formation overwhelms mitochondrial antioxidant capacity, apoptosis is triggered $^{16,35}$. ROS production above mitochondrial antioxidant capacity triggers the opening of the mitochondrial permeability transition (MPT) pore and induces the release of cytochrome $c$ from mitochondria to the cytosol, activating the mitochondria-dependent intrinsic apoptosis pathway and leading to cell death ${ }^{33,35,36}$. There is evidence that inhibition of mitochondrial ROS and reduction of mitochondrial oxidative stress reduces cisplatin toxicity $^{11-13}$. In the present study, Mito-T, a mitochondriatargeting antioxidant molecule, prevented cisplatininduced changes in Bax and Bcl-2 expression and cytochrome $c$ release, resulting in reduced apoptosis of kidney tubular epithelial cells. These changes were higher in $I d h 2^{-/-}$mice than in Idh2 $2^{+/+}$mice. In addition, Mito-T treatment inhibited the increase in Drp1 expression. Furthermore, the protective effect of Mito- $\mathrm{T}$ was greater 
in $I d h 2^{-/-}$mice compared with their wild-type littermates. These data indicate that cisplatin-induced kidney cell apoptosis is associated with impaired IDH2 function and Idh2 gene deletion aggravates kidney apoptosis.

Taken together, our data demonstrate that cisplatin impairs the mitochondrial IDH2-NADPH-GSH antioxidant system, leading to mitochondrial oxidative stress and consequently, renal cell apoptosis, dysfunction, and damage. This suggests that the mitochondrial IDH2NADPH-GSH antioxidant system is a useful target axis to prevent cisplatin nephrotoxicity.

\section{Materials and methods}

\section{Animal experiments}

All experiments were conducted using 12-week-old female Idh2-gene-deficient $\left(I d h 2^{-/-}\right)$mice and wild-type $\left(I d h 2^{+/+}\right)$littermates ${ }^{37}$. The study was approved by the Institutional Animal Care and Use Committee of Kyungpook National University. Mice were allowed free access to water and standard mouse chow. Cisplatin (Cisdiamminedichloroplatinum II, $20 \mathrm{mg} / \mathrm{kg}$ body weight; Sigma, St. Louis, MO, USA) was administered to the mice once intraperitoneally. Some mice were injected intraperitoneally with (2-(2,2,6,6-Tetramethylpiperidin-1-oxyl4-ylamino)-2-oxoethyl) triphenylphosphonium chloride (Mito-T, $0.7 \mathrm{mg} / \mathrm{kg}$ body weight; Sigma) once daily, beginning 7 days before cisplatin injection and continuing until experiments were completed. Mice were killed 3 days after cisplatin injection. Kidneys were either snapfrozen in liquid nitrogen for biochemical analysis or fixed in PLP (4\% paraformaldehyde, $75 \mathrm{mM}$ L-lysine, $10 \mathrm{mM}$ sodium periodate) for histological studies.

\section{Renal functional parameters}

Blood was taken from the retro-orbital venous plexus using a heparinized capillary glass tube. BUN and $\mathrm{PCr}$ were measured using a Vitros 250 Chemistry Analyzer (Johnson \& Johnson, New Brunswick, NJ, USA).

\section{Histology}

PLP-fixed kidneys were embedded in paraffin and cut into 3- $\mu \mathrm{m}$-thick sections using a microtome (RM2165; Leica, Wetzlar, Germany). Kidney sections were stained with periodic acid Schiff stain (PAS) according to the manufacturer's instructions. Images were captured using the i-Solution software (IMT, Vancouver, Canada). Tubule damage was scored by the following criteria: 0 , no damage; 1 , mild damage with rounded epithelial cells and dilated tubular lumen; 2, moderate damage with flattened epithelial cells, dilated lumen, and congestion of the lumen; and 3, severe damage with flat epithelial cells lacking nuclear staining and congestion of the lumen. More than ten fields per kidney section were analyzed.

\section{Mitochondria isolation from kidney tissue}

Mitochondrial and cytosolic fractions were prepared as described previously ${ }^{38}$. Briefly, kidney samples were homogenized thrice in sucrose buffer $(0.2 \mathrm{M}$ sucrose, $1 \mathrm{mM}$ EGTA, $10 \mathrm{mM}$ HEPES, pH 7.4). A Teflon Homogenizer (Daihan Scientific, Seoul, Korea) was used at 1600 r.p.m. and this step was performed in an ice bath. The homogenate was centrifuged at $600 \times g$ for $10 \mathrm{~min}$ at $4{ }^{\circ} \mathrm{C}$. The supernatant was centrifuged at $7000 \times g$ for $10 \mathrm{~min}$. To obtain the purified cytosolic fraction, the supernatant was centrifuged again at $7000 \times g$ for $10 \mathrm{~min}$. The pellet was washed twice and centrifuged again at $7000 \times g$ for $10 \mathrm{~min}$. It was then suspended in sonication buffer $(0.1 \%$ Triton X-100 in PBS) and sonicated twice using a 4710 series sonicator (Cole-Palmer, Chicago, IL) at $40 \%$ maximum setting for $10 \mathrm{~s}$. Subsequently, after centrifugation at $15,000 \times g$ for $30 \mathrm{~min}$, the supernatant containing mitochondria was collected. Fractions were confirmed by western blot analysis using anti-COX IV (Abcam, Cambridge, MA, USA) as a marker of mitochondria and anti-GAPDH (NOVUS, Littleton, CO, USA) as a marker of cytosol.

\section{Measurement of hydrogen peroxide levels in the kidney}

Hydrogen peroxide levels were measured in kidney homogenates using xylenol orange (Sigma), a ferricsensitive $\mathrm{dye}^{39}$. Measurement was based on the following principles: $\mathrm{H}_{2} \mathrm{O}_{2}$ oxidizes iron (II) to iron (III) in the presence of sorbitol, which acts as a catalyst; and iron (III) makes a purple complex with xylenol orange.

\section{Western blot analysis}

Western blotting was performed using anti-4hydroxynonenal (4-HNE; Abcam), anti-peroxiredoxin (Prx- $\mathrm{SO}_{3}$, Abcam), anti-MnSOD (Calbiochem, San Diego, CA), anti-copper-zinc superoxide dismutase (CuZnSOD; Chemicon, Temecula, CA), anti-histone H1 (Santa Cruz Biotechnology, Santa Cruz, CA, USA), antimitochondrial $\mathrm{NADP}^{+}$-dependent isocitrate dehydrogenase (IDH2) ${ }^{40}$, anti-Opa1 (BD Bioscience, Franklin Lakes, NJ, USA), anti-Drp1 (Cell Signaling Technology, Danvers, MA, USA), anti-Bax (5B7; Santa Cruz), anti-Bcl2 (Cell Signaling Technology), anti-cytochrome $c$ (BD Bioscience), anti-cleaved caspase-3 (Merck Millipore, Darmstadt, Germany), anti- $\beta$-actin (Sigma), and antiGAPDH (Novus, Littleton, CO, USA) antibodies.

\section{Measurement of IDH1, IDH2, and IDH3 activity}

The determinations of IDH1 and IDH2, and IDH3 activity were based on the productions of NADPH and $\mathrm{NADH}$, respectively ${ }^{41}$. Briefly, cytosolic fraction for IDH1 activity and mitochondrial fraction for IDH2 activity were incubated in the reaction buffers containing $40 \mathrm{mM}$ Tris (pH 7.4), $100 \mathrm{mM} \mathrm{NADP}{ }^{+}, 100 \mathrm{mM} \mathrm{MgCl}$, and $200 \mathrm{mM}$ 
isocitrate (Sigma), respectively. Their activities were defined as the changes in absorbance at $340 \mathrm{~nm}$ over $1 \mathrm{~min}$ at $37^{\circ} \mathrm{C}$. For the determination of IDH3 activity, mitochondrial fraction was incubated in the reaction buffer containing $40 \mathrm{mM}$ Tris ( $\mathrm{pH} 7.4), 100 \mathrm{mM} \mathrm{NAD}^{+}$, $100 \mathrm{mM} \mathrm{MgCl}$, and $200 \mathrm{mM}$ isocitrate. Activity was defined as the change in absorbance at $340 \mathrm{~nm}$ over $1 \mathrm{~min}$ at $37^{\circ} \mathrm{C}$.

\section{Measurement of mitochondrial NADPH concentration}

Measurement of NADPH concentration was based on a glucose dehydrogenase cycling reaction. The level of NADPH in kidney mitochondria was determined using an EnzyChrom $^{\text {ix }}$ NADP/NADPH Assay Kit (BioAssay Systems, Hayward, CA, USA) according to the manufacturer's instruction. In brief, freshly isolated kidney mitochondria was suspended in $100 \mu \mathrm{L}$ NADPH extraction buffer for NADP determination or $100 \mu \mathrm{L}$ NADPH extraction buffer for NADPH determination, and then heated at $60^{\circ} \mathrm{C}$ for $5 \mathrm{~min}$. After heating $20 \mu \mathrm{L}$ assay buffer and $100 \mu \mathrm{L}$ of the NADP, opposite extraction buffer was added to neutralize the extracts. After centrifugation of the sample at 14,000 r.p.m. for $5 \mathrm{~min}$, the supernatant was used for determination. In 96-well plate, $40 \mu \mathrm{L}$ samples were transferred and added $80 \mu \mathrm{L}$ working reagent $(60 \mu \mathrm{L}$ assay buffer, $1 \mu \mathrm{L}$ enzyme mix, $10 \mu \mathrm{L}$ glucose, and $14 \mu \mathrm{L}$ MTT). The plate was briefly tapped to mix and read the optical density (OD) at $565 \mathrm{~nm}$ at time zero and $30 \mathrm{~min}$. The concentration of $\mathrm{NADP}(\mathrm{H})$ was calculated using the change of OD for $30 \mathrm{~min}$.

\section{Measurement of GSSG and total glutathione (tGSH) levels in the kidney}

Measurement of oxidized glutathione (GSSG) and total glutathione (tGSH) are based on enzymatic recycling method for quantification of glutathione; GR reduces oxidized glutathione (GSSG) to reduced glutathione (GSH). The sulfhydryl group of GSH reacts with DTNB (5,5'-dithiobis-2-nitrobenzoic acid) to produce a yellowcolored 5-thio-2-nitrobenzoic acid (TNB) that absorbs at $405 \mathrm{~nm}$. The rate of TNB production is directly proportional to the concentration of glutathione in the sample. The ratio of GSSG to tGSH was measured using the glutathione (GSSG/GSH) detection kit (Enzo Life Sciences, Farmingdale, New York, USA) according to the manufacturer's instruction. In brief, freshly isolated mitochondrial fractions were suspended in ice-cold 5\% metaphosphoric acid ( $20 \mu \mathrm{L} / \mathrm{mg}$ tissue) and centrifuged at $12,000 \times g$ for $15 \mathrm{~min}$ at $4{ }^{\circ} \mathrm{C}$. Supernatants reacted to the freshly prepared reaction mix. The absorbances were detected at $405 \mathrm{~nm}$ every minute for $10 \mathrm{~min}$. Determination of GSSG was the same protocol with GSH assay with an exception in which mitochondrial fraction was suspended in 5\% metaphosphoric acid containing $2 \mathrm{M} \mathrm{4-}$ vinylpyridine.

\section{Measurement of glutathione peroxidase (GSH-Px) and glutathione reductase (GR) activity in kidney mitochondria}

GSH-Px activity was measured in a reaction mixture, including $0.1 \mathrm{M}$ potassium phosphate buffer ( $\mathrm{pH}$ 7.0) containing $1 \mathrm{mM}$ EDTA, $0.25 \mathrm{U}$ GR, $10 \mathrm{mM} \mathrm{GSH}$, and $1.5 \mathrm{mM}$ NADPH. Measurement of GR activity was performed in the same way, using $0.1 \mathrm{M}$ potassium phosphate buffer ( $\mathrm{pH} 7.0$ ) containing $1 \mathrm{mM}$ EDTA, $10 \mathrm{mM}$ GSSG, and $10 \mathrm{mM}$ NADPH. Activities were measured as the change in absorbance at $340 \mathrm{~nm}$ in $1 \mathrm{~min}$ at $37^{\circ} \mathrm{C}$.

\section{Immunofluorescence}

Paraffin-embedded kidney sections were deparaffinized, rehydrated, and washed with distilled water. Sections were then incubated with PBS containing $0.2 \%$ Triton X-100 for $5 \mathrm{~min}$ and washed with PBS for $10 \mathrm{~min}$. For antigen retrieval, kidney sections were heated in $0.01 \mathrm{M}$ sodium citrate buffer $(\mathrm{pH}$ 6.0) for $10 \mathrm{~min}$ using an autoclave. Sections were then cooled and washed thrice with PBS. Sections were blocked with PBS containing $1 \%$ bovine serum albumin for $30 \mathrm{~min}$. Kidney sections were incubated with an anti-8-hydroxy-2'-deoxyguanosine (8OHdG, Abcam) antibody in a humidified chamber at $4{ }^{\circ} \mathrm{C}$ overnight. After three washes, sections were incubated with FITC-conjugated secondary antibodies for $1 \mathrm{~h}$ at room temperature and then washed with PBS in the dark. Sections were mounted with the Prolong Gold anti-fade reagent (Invitrogen, Carlsbad, CA, USA). Images were captured using a Leica DM2500 microscope.

\section{Transmission electron microscopy}

Three days after cisplatin or $0.9 \%$ saline (vehicle) administration, kidneys were fixed with $2.5 \%$ glutaraldehyde at $4{ }^{\circ} \mathrm{C}$ for $12 \mathrm{~h}$ and cut into $1 \mathrm{~mm}^{3}$-sized blocks. Kidney samples were washed in $0.1 \mathrm{M}$ phosphate buffer and post fixed in aqueous $2 \%$ osmium tetroxide for $90 \mathrm{~min}$. Samples were then washed thrice with phosphate buffer and dehydrated through a graded series of $50-100 \%$ ethanol and $100 \%$ propylene oxide and then infiltrated in 1:1, 1:2, and 1:3 mixtures of propylene oxide: Epon Resin 828 (Polysciences Inc., Warrington, PA, USA) for $1 \mathrm{~h}$, respectively. Samples were then incubated with 100\% Epon Resin 828 for $8 \mathrm{~h}$, embedded in molds. Samples were cured at 35 and $45^{\circ} \mathrm{C}$ for $12 \mathrm{~h}$, with additional hardening at $60^{\circ} \mathrm{C}$ for 2 days. Samples were cut into ultrathin $(60 \mathrm{~nm})$ sections and double-stained with $2 \%$ uranyl acetate and 1\% lead citrate. Electron micrographs of mitochondria were obtained from proximal tubular cells in the cortex using a transmission electron microscope (H-7000, Hitachi, Japan) at $75 \mathrm{kV}$. 


\section{Terminal deoxynucleotidyl transferase dUTP nick end labeling (TUNEL) assay}

TUNEL assays were performed using an in situ cell death detection kit (Roche, Basel, Switzerland) according to the manufacturer's instructions. In brief, kidney sections were incubated with the TUNEL reagent mixture at room temperature for $30 \mathrm{~min}$ and washed thrice with PBS for $5 \mathrm{~min}$ each time. Images were captured using a microscope (Leica DM2500). TUNEL-positive cells were counted with i-Solution software (IMT, Cicero, NY, USA).

\section{Statistical analysis}

Statistical differences among groups were evaluated by Student's ttest. Results were expressed as the means \pm SE. Differences were considered statistically significant at $P$ values $<0.05$.

\section{Acknowledgements}

This study was supported by a National Research Foundation of Korea (NRF) Grant (NRF-2017R1A2A2A05069707 and 2017R1D1A1B03031048) funded by the Korean government.

\section{Author details \\ 'Department of Anatomy, Cardiovascular Research Institute and BK21 Plus, School of Medicine, Kyungpook National University, 680 Gukchaebosang-ro, Junggu, Daegu 41944, Republic of Korea. ²Department of Molecular Medicine and MRC, Keimyung University School of Medicine, 1095 Dalgubeol-daero, Dalseogu, Daegu 42601, Republic of Korea. ${ }^{3}$ Department of Biochemistry, School of Life Sciences and Biotechnology, College of Natural Sciences, Kyungpook National University, Daegu, Republic of Korea}

\section{Conflict of interest}

The authors declare that they have no conflict of interest.

\section{Publisher's note}

Springer Nature remains neutral with regard to jurisdictional claims in published maps and institutional affiliations.

Received: 20 December 2017 Revised: 22 March 2018 Accepted: 27 March 2018

Published online: 25 April 2018

\section{References}

1. Miller, R. P., Tadagavadi, R. K., Ramesh, G. \& Reeves, W. B. Mechanisms of cisplatin nephrotoxicity. Toxins 2, 2490-2518 (2010).

2. Santos, N. A. et al. Hydroxyl radical scavenger ameliorates cisplatin-induced nephrotoxicity by preventing oxidative stress, redox state unbalance, impairment of energetic metabolism and apoptosis in rat kidney mitochondria. Cancer Chemother. Pharmacol. 61, 145-155 (2008).

3. Aydinoz, S. et al. Effects of different doses of hyperbaric oxygen on cisplatininduced nephrotoxicity. Ren. Fail. 29, 257-263 (2007).

4. Brady, H. R. et al. Mitochondrial injury: an early event in cisplatin toxicity to renal proximal tubules. Am. J. Physiol. 258(5 Pt 2), F1181-1187 (1990).

5. Marullo, R. et al. Cisplatin induces a mitochondrial-ROS response that contributes to cytotoxicity depending on mitochondrial redox status and bioenergetic functions. PLOS ONE 8, e81162 (2013).

6. Yonezawa, A. Platinum agent-induced nephrotoxicity via organic cation transport system. J. Pharm. Soc. Jpn. 132, 1281-1285 (2012).

7. Safirstein, R., Miller, P. \& Guttenplan, J. B. Uptake and metabolism of cisplatin by rat kidney. Kidney Int. 25, 753-758 (1984).
8. Pabla, N., Murphy, R. F., Liu, K. \& Dong, Z. The copper transporter Ctr1 contributes to cisplatin uptake by renal tubular cells during cisplatin nephrotoxicity. Am. J. Physiol. Ren. Physiol. 296, F505-511 (2009).

9. Brooks, C., Cho, S. G., Wang, C. Y., Yang, T. \& Dong, Z. Fragmented mitochondria are sensitized to Bax insertion and activation during apoptosis. Am. J. Physiol. Cell Physiol. 300, C447-455 (2011).

10. Chen, Y. R. \& Zweier, J. L. Cardiac mitochondria and reactive oxygen species generation. Circ. Res. 114, 524-537 (2014).

11. Tabara, L. C. et al. Mitochondria-targeted therapies for acute kidney injury. Expert Rev. Mol. Med. 16, e13 (2014).

12. Mari, M., Morales, A., Colell, A., Garcia-Ruiz, C. \& Fernandez-Checa, J. C. Mitochondrial glutathione, a key survival antioxidant. Antioxid. Redox Signal. 11 2685-2700 (2009).

13. Yang, Y., Liu, H., Liu, F. \& Dong, Z. Mitochondrial dysregulation and protection in cisplatin nephrotoxicity. Arch. Toxicol. 88, 1249-1256 (2014).

14. Birben, E., Sahiner, U. M., Sackesen, C., Erzurum, S. \& Kalayci, O. Oxidative stress and antioxidant defense. World Allergy Organ. J. 5, 9-19 (2012).

15. Harris, I. S. et al. Glutathione and thioredoxin antioxidant pathways synergize to drive cancer initiation and progression. Cancer Cell 27, 211-222 (2015).

16. Han, S. J. et al. Mitochondrial $\mathrm{NADP}^{+}$-dependent isocitrate dehydrogenase deficiency exacerbates mitochondrial and cell damage after kidney ischemiareperfusion injury. J. Am. Soc. Nephrol. 28, 1200-1215 (2017).

17. Reitman, Z. J. \& Yan, H. Isocitrate dehydrogenase 1 and 2 mutations in cancer: alterations at a crossroads of cellular metabolism. J. Natl Cancer Inst. 102, 932-941 (2010).

18. Jo, S. H. et al. Control of mitochondrial redox balance and cellular defense against oxidative damage by mitochondrial NADP+ -dependent isocitrate dehydrogenase. J. Biol. Chem. 276, 16168-16176 (2001).

19. Kim, J., Kim, J. I., Jang, H. S., Park, J. W. \& Park, K. M. Protective role of cytosolic $\mathrm{NADP}(+)$-dependent isocitrate dehydrogenase, IDH1, in ischemic preconditioned kidney in mice. Free Radic. Res. 45, 759-766 (2011)

20. Park, J. B. et al. IDH2 deficiency impairs mitochondrial function in endothelial cells and endothelium-dependent vasomotor function. Free Radic. Biol. Med. 94, 36-46 (2016).

21. Winkler, B. S., DeSantis, N. \& Solomon, F. Multiple NADPH-producing pathways control glutathione (GSH) content in retina. Exp. Eye Res. 43, 829-847 (1986).

22. Valavanidis, A., Vlachogianni, T. \& Fiotakis, C. 8-hydroxy-2' -deoxyguanosine (8OHdG): a critical biomarker of oxidative stress and carcinogenesis. J. Environ. Sci. Health C 27, 120-139 (2009).

23. Archer, S. L. Mitochondrial dynamics--mitochondrial fission and fusion in human diseases. New Engl. J. Med. 369, 2236-2251 (2013).

24. Brooks, C., Wei, Q., Cho, S. G. \& Dong, Z. Regulation of mitochondrial dynamics in acute kidney injury in cell culture and rodent models. J. Clin. Investig. 119 1275-1285 (2009).

25. Qian, W. et al. Mitochondrial density determines the cellular sensitivity to cisplatin-induced cell death. Am. J. Physiol. Cell Physiol. 289, C1466-1475 (2005).

26. Kawai, Y., Nakao, T., Kunimura, N., Kohda, Y. \& Gemba, M. Relationship of intracellular calcium and oxygen radicals to Cisplatin-related renal cell injury. J. Pharmacol. Sci. 100, 65-72 (2006).

27. Pascoe, J. M. \& Roberts, J. J. Interactions between mammalian cell DNA and inorganic platinum compounds. I. DNA interstrand cross-linking and cytotoxic properties of platinum(II) compounds. Biochem. Pharmacol. 23, 1359-1365 (1974).

28. Kruidering, M., Van de Water, B., de Heer, E., Mulder, G. J. \& Nagelkerke, J. F. Cisplatin-induced nephrotoxicity in porcine proximal tubular cells: mitochondrial dysfunction by inhibition of complexes I to IV of the respiratory chain. J. Pharmacol. Exp. Ther. 280, 638-649 (1997).

29. Mukhopadhyay, P. et al. Mitochondrial-targeted antioxidants represent a promising approach for prevention of cisplatin-induced nephropathy. Free Radic. Biol. Med. 52, 497-506 (2012).

30. Zsengeller, Z. K. et al. Cisplatin nephrotoxicity involves mitochondrial injury with impaired tubular mitochondrial enzyme activity. J. Histochem. Cytochem 60, 521-529 (2012).

31. Singh, R, Mailloux, R. J., Puiseux-Dao, S. \& Appanna, V. D. Oxidative stress evokes a metabolic adaptation that favors increased NADPH synthesis and decreased NADH production in Pseudomonas fluorescens. J. Bacteriol. 189, 6665-6675 (2007).

32. Martinou, J. C. \& Youle, R. J. Mitochondria in apoptosis: BCl-2 family members and mitochondrial dynamics. Dev. Cell 21, 92-101 (2011). 
33. Scorrano, L. \& Korsmeyer, S. J. Mechanisms of cytochrome c release by proapoptotic BCL-2 family members. Biochem. Biophys. Res. Commun. 304 437-444 (2003).

34. Wang, P. et al. Dynamin-related protein Drp1 is required for Bax translocation to mitochondria in response to irradiation-induced apoptosis. Oncotarget $\mathbf{6}$ 22598-22612 (2015).

35. Fleury, C., Mignotte, B. \& Vayssiere, J. L. Mitochondrial reactive oxygen species in cell death signaling. Biochimie 84, 131-141 (2002).

36. Yuan, $\mathrm{H}$. et al. Mitochondrial fission is an upstream and required event for bax foci formation in response to nitric oxide in cortical neurons. Cell Death Differ. 14, 462-471 (2007).

37. Kim, S. et al. Suppression of tumorigenesis in mitochondrial NADP (+)-dependent isocitrate dehydrogenase knock-out mice. Biochim. Biophys. Acta 1842, 135-143 (2014).
38. Frezza, C., Cipolat, S. \& Scorrano, L. Organelle isolation: functional mitochondria from mouse liver, muscle and cultured fibroblasts. Nat. Protoc. 2, 287-295 (2007).

39. Kim, J., Seok, Y. M., Jung, K. J. \& Park, K. M. Reactive oxygen species/ oxidative stress contributes to progression of kidney fibrosis following transient ischemic injury in mice. Am. J. Physiol. Ren. Physiol. 297, F461-470 (2009)

40. Shin, A. H. et al. Regulation of high glucose-induced apoptosis by mitochondrial NADP+-dependent isocitrate dehydrogenase. Biochem. Biophys. Res. Commun. 325, 32-38 (2004).

41. Lee, S. M. et al. Cytosolic NADP(+)-dependent isocitrate dehydrogenase status modulates oxidative damage to cells. Free Radic. Biol. Med. 32, 1185-1196 (2002). 